\title{
The Potential of Online Academic Communities for Teaching Staff: Findings from a Pilot Study of the SocialLearn Platform
}

\section{Vikki McCall*, Gerry Mooney, Paul Rutherford and Alison Gilmour}

\section{Dr Vikki McCall}

School of Applied Social Science, University of Stirling, Stirling, FK8 4LN, UK Tel: +44 (0) 1786467698

E-mail: vikki.mccall@stir.ac.uk

Twitter: @vikki_mccall

* Corresponding author

\section{Dr Gerry Mooney}

Department of Social Policy and Criminology, Faculty of Social Sciences, The Open University in Scotland, 10 Drumsheugh Gardens, Edinburgh, EH3 7QJ

Telephone: 01315497163

Email: Gerry.Mooney@ open.ac.uk

\section{Paul Rutherford}

School of History and Politics, University of Stirling, Stirling, FK8 4LN, UK E-mail: p.rutherford@open.ac.uk

\section{Dr Alison Gilmour}

Learning Development Team

The Open University in Scotland

10 Drumsheugh Gardens

Edinburgh, EH3 7QJ

Telephone: +44 (0) 1312263851

E-mail: Alison.Gilmour@open.ac.uk

\section{Biographical Notes:}

Vikki McCall is a Lecturer in Social Policy and Housing at the University of Stirling, UK. She teaches the postgraduate diploma in housing studies, which utilises a mixture of online and face-to-face learning. Vikki is also an Associate Lecturer for The Open University and has published work around social policy, social inclusion, museums, policy makers' perceptions of culture and cultural data.

Gerry Mooney is a Senior Lecturer in Social Policy and Criminology in the Faculty of Social Sciences at The Open University. He has written widely on issues ranging from urban studies and the city, through social movements, poverty and social inequality, to Scottish devolution and class and work. 
Paul Rutherford teaches at The Open University and Stirling University. He teaches within the areas of environmental politics and international relations, with an emphasis on the changing role of multinational corporations within global governance.

Alison Gilmour is a Project Officer in the Learning Development Team at The Open University in Scotland. Her role focuses on developing and managing academic enhancement projects covering a diverse range of topics including digital learning and reflective teaching practice, as well as being involved in professional development activities. The latter has included working with Open University colleagues on a QAA funded cross-sector project on the professional development of teaching staff in Scottish HE. 


\title{
The potential of online academic communities for teaching staff: findings from a pilot study of the SocialLearn platform
}

\begin{abstract}
The purpose of this paper is to offer some insight from an evaluation that explored the viability, usefulness and potential of the online platform SocialLearn in providing an online community for Open University Associate Lecturers (part-time teaching staff). Findings from two focus groups and a staff survey highlighted both the potential of an online community and the barriers to successful implementation. In applying a qualitative analysis of the 'Communities of Inquiry' (CoI) framework, the pilot project highlighted the importance of social presence and cognitive presence, with minimal elements of a teaching presence within the online staff community. Key learning outcomes around privacy, usability and multi-level communications were found to be central in creating a successful online academic environment for teaching staff.
\end{abstract}

Key words: online community; staff development; social media; communities of inquiry

\section{Introduction}

This paper outlines some insights into the process and usefulness of creating an online community for teaching staff. Online communities are more important than ever before, with e-learning and online teaching evolving into a new era with the advent of Massive Online Open Courses (MOOCs). There are increasing investigations of how online communities have potential for students (Garrison and Arbaugh 2007; Aykol and Garrison 2008; Zingaro and Oztok 2012) but there remains a gap in knowledge around online communities for teaching staff ${ }^{1}$.

Online communities are especially important for The Open University (OU), an international university based in the UK. The Open University (OU) was founded in the late 1960s on the principles of open access to higher education through supported distance learning. For many students and teachers, online communities have become integrated into their daily activities as one of the most common ways of communicating virtually, through different platforms such as, Facebook, Twitter and forums. However, as yet, none of these platforms have been able to provide both a dynamic and controlled academic platform for staff. This paper offers some key findings from an evaluation of a six-month pilot exploring the viability, usefulness and potential of an Open University virtual platform called SocialLearn in building an online staff community.

To enable evaluation, the pilot project goal was to explore the potential for developing an academic staff community among OU part-time tutors, termed in the OU 'Associate Lecturers' (ALs), whose key role is to support student learning on modules. The aim was to foster a sense of an academic community amongst tutor peers within the OU. The pilot project included a number of Social Sciences Associate Lecturers (ALs) working for the OU in Scotland, who in October 2012 were invited to join and interact within a specially formed group called the 'Social

\footnotetext{
${ }^{1}$ This paper is a revised and expanded version of a paper entitled 'The potential of online academic communities: findings from a pilot study of the SocialLearn platform' presented at the Enhancment and Innovation in Higher Education conference 11-13th June 2013..
} 
Sciences Academic Engagement Pilot Community'. The pilot project captured staff engagement and feedback through the 'virtual community' as well as focus groups and a final survey. The key findings identified in the evaluation are intended to facilitate a discussion on the usefulness of social networking in enabling potential development of online communities of teaching staff.

\section{The potential of online communities}

In the OU, social networking is used to facilitate collaborative practice amongst geographically disconnected individuals including, for instance, OU ALs. There are over 7,000 ALs working for the OU, of which around 500 are in Scotland. Student learning is facilitated and supported by these tutors and this has been seen to be a successful model for distance teaching. For example, Donovan et al. (2008), in a study of OU Science ALs, found that the flexible nature of the role was integral for academic progression for women. However, this flexibility can result in feelings of isolation; over the years ALs have described experiencing a sense of isolation from the University, at least in terms of feeling part of a vibrant academic community, where they can participate in a culture of debate and argument. The geographical spread of tutors across the length and breadth of Scotland means that face-to-face participation in events such as workshops and seminars, as well as the opportunity to meet more informally with colleagues, is not always possible or practical.

An online learning community is a viable option to try and tackle these feelings of isolation and can be defined as:

"a body of individuals who use computer networks to share ideas, information, and insights about a given theme or topic to support the ongoing learning experiences of all the members" (Fontana 1997: 4).

Online communities could potentially foster creativity, help problem-solving, facilitate decision-making and act as 'incubators' for social participation (Fontana 1997: 3). Successful academic communities have been fostered from large conference events (Thatcher et al. 2011). Furthermore, research has shown that web-based networks have helped teachers develop knowledge, competencies and professional development in informal communities (Pereira Coutinho and Santana Lisbôa 2013). Social media platforms have great potential for collaborative learning and the 'social construction of meaning' (Palloff and Pratt 2007: 19). There is, therefore, potential to utilise online environments to build successful, social and collaborative communities. Although this potential is often discussed in relation to students, we aimed to assess their potential with staff.

Despite this potential, online staff development and collaboration can be looked upon with scepticism from faculty and professional communities due to a wide variety of reasons. These include intellectual and cost reasons as well as feeling a lack of support and worries about change (Anderson et al. 2010). Furthermore, most of the research on online communities has focused on student online engagement. For example, the Communities of Inquiry (CoI) framework has focused on student engagement despite its potentially wider applicability. The development of Communities of Inquiry (CoI) (Garrison, Anderson and Archer, 2000; Garrison and Anderson 2003; Garrison and Arbaugh 2007) offers one of the first clear analytical frameworks to investigate effective online communities. The framework is dynamic 
and aims to help analyse online experiences (Aykol and Garrison 2008). The framework includes three factors for online communities including social presence, cognitive presence and teaching presence (see appendix A for full breakdown). Although Communities of Inquiry (CoI) are traditionally focused on online student communities, this project applied the framework to online staff communities.

The potential of online staff communities can be seen in successful social media platforms such as Facebook, Twitter, LinkedIn as well, at the OU, a wide and diverse range of discussion forums. However, as yet, none of these platforms have been able to provide a controlled and dynamic staff community for the OU. The OU has proposed an answer to this problem by offering staff and students the chance to interact on its new online platform SocialLearn, which aims to let users share information and engage on both a social and professional level. For ALs there was also an element of professional development and the potential to share research, scholarship and ideas.

An effective academic environment is very important as online concerns include issues in people developing their 'social presence' as they need to define themselves and engage emotionally. This can lead to performance anxiety on social media platforms (Palloff and Pratt 2007) and reluctance to engage. 'Social presence' is also one of the key elements of $\mathrm{CoI}$ and is about "affective expression, open communication and group cohesion" (Aykol and Garrison, 2008. p. 4). Nonengagement can lead to isolation, which can also affect how people engage with wider communities. There is also ongoing privacy and commercial considerations linked to social media platforms.

ALs within the OU are unique in that they often teach in isolated environments, at least in terms of face-to-face interaction, especially in geographically dispersed areas such as Scotland and Ireland. ALs have limited means of interacting formally with other peers in this regard. Furthermore, their students may also be geographically dispersed. The feelings of isolation that many experience together with the perceived desire for a greater sense of being part of an academic community, led to the piloting of SocialLearn as a new online environment for Open University ALs. McInnerney and Roberts (2004) show that combating isolation is one of the main factors for successful or unsuccessful online learning environments. The social elements of online learning communities are central to successful online communication. If a sense of 'self' is encouraged within the online environment, this assists the learning process by combating feelings of isolation. With this in mind, the pilot project was intended to facilitate a discussion on the usefulness of social networking in enabling continuous professional and social development and the creation of an academic community for teaching staff.

\section{Online community platforms}

An online learning community is an "emerging network and accompanying applications are powerful tools for teaching and learning, which place even greater responsibility on individuals" (Fontana 1997:3). This individual responsibility is important and linked to the establishment of self within online environments as: 
"The technology that makes virtual communities possible has the potential to bring enormous leverage to ordinary citizens at relatively low cost... But the technology will not in itself fulfil that potential, this latent technical power must be used intelligently and deliberately by an informed population" (H. Rheingold, in Fontana 1997: 1).

There is not much known about how this 'latent technical power' is really used or implemented. The quote suggests that although there is a lot of potential in online platforms, it is the users of, and participants in, that community that are central. SocialLearn was created as a potential route to facilitate this professional and social development in an online environment but also to enhance the sense of a shared academic community among a network of likeminded peers.

SocialLearn is a new platform made and hosted by the OU and is still in its beta phase. SocialLearn is a hybrid of different media platforms. For example, you can build a profile such as on Facebook and follow people as with Twitter. Public collections can be seen in multiple 'communities' across the platform. A separate, restricted and controlled 'community' was created for the ALs involved in the pilot scheme. This was built by the research team to include both learning and social aspects of a social community (please see appendix B to see full layout of the community). The layout of the SocialLearn platform shows a mix of academic, social and political content. This platform aimed to have both social and scholarship elements within it and this pilot project aimed to assess the capacity of this type of interactive and social community.

\section{Methodology}

This evaluation has been conducted using a mixed method approach. The mixed methods can be shown as three phases. Phase 1 included an initial period of time on the formation of project goals and methods and an examination of supporting literature. The pilot sample of 55 Scottish social sciences ALs was confirmed, drawn from modules across the undergraduate curriculum and from across Scotland. Furthermore, the SocialLearn community platform was created and populated by the research team in preparation for AL participation. The 'Social Sciences Academic Engagement Pilot Community' group has been open to ALs since November 2012 and is designed to allow ALs to share ideas, experiences, knowledge and interesting thoughts, ideas and useful web and other links (for full visual please see appendix B). This has been the main 'interface' component of the project and has been monitored by the research team.

For phase 2 it was decided that the best way to maximise staff participation was to utilise focus group methods. Two focus groups that lasted an hour each were conducted in November 2012 with the pilot group (approximately 40 people in total). The focus groups explored a range of issues including AL views on the use of social media in general, possible barriers and potential AL participation on platforms such as SocialLearn. The focus group data was fully transcribed and analysed on QSR NVivo (a qualitative software package) to explore cross-cutting themes. The analysis approach utilised grounded theory to embed the findings in the empirical data. Grounded theory has been a successful analysis technique for explore the expectations and integration of online learners (Scott 2007). The transcribed manuscripts were uploaded into QSRNVivo and coded nvivo. The main coding categories included 
trust, monitoring social, sharing and are outlined in the focus group findings section below. The CoI framework was the brought in as a descriptive analytical theory after this initial analysis due to the dominant themes found. This helped to give further insights to the findings in regards to creating an effective online community.

For phase 3 of the project a short survey was designed with several key objectives in mind. The first was to compliment the focus group data and offer a quantitative measure of AL opinion. This was also designed to be carried out after ALs had experienced some preliminary engagement with SocialLearn. The survey also allowed room for ALs to reflect on some of the wider debates around building a successful online community. With these objectives in mind, the core survey questions were organised around key issues and dilemmas drawn from the initial focus group meetings. The survey was sent out between April and May 2013 to the 55 ALs including those who participated in the initial focus group discussions and those who did not attend. The survey had a response rate of $40 \%$.

Due to the small sample, care was taken not to outline the demographics of the respondents. The involvement of the OU line manager in the commissioning of the project can potentially lead to the identification of individuals taking part in the research. Therefore due to ethical reasons and the potential harm that could be caused by the AL's honest answers about their place of work demographic profiles were not included.

The final analytics and engagement of the SocialLearn platform are outlined in appendix $\mathrm{C}$. The tables show the results from a six month period from November 2012 to April 2013. The results show that from the 55 members of the pilot group there were 17 active users (a take up of $31 \%$ ). This is slightly higher than the average $25 \%$ take-up rate for corporate e-learning and academic online platforms found in other research (Ubell 2010). The 17 active users created six collections, three events, four thoughts and 51 comments. This averages three comments per active user over the six month period. To analyse the data for this paper, we used a theoretical framework that helped us understand the social, cognitive and teaching elements within the online community.

\subsection{Theoretical framework}

One of the difficulties within this project has been the understanding of what type of community the SocialLearn platform could offer part-time staff such as ALs. Assumptions included claims that the platform would facilitate academic, social, learning and teaching engagement. This is why the Communities of Inquiry (CoI) framework has been helpful in setting out and giving insight to the different elements of an online community. The Community of Inquiry (CoI) theoretical framework "represents a process of creating a deep and meaningful (collaborativeconstructivist) learning experience through the development of three interdependent elements - social, cognitive and teaching presence" (see Garrison et al. 2013).

The CoI framework has been used as a purely quantitative measure, but a mixed method approach has been the most popular (Aykol and Garrison 2008). Annand (2011) offers a critique of the CoI framework and its assumptions of objective and testable results that are socially constructed interactions. Despite these challenges, there has been on-going theoretical debate and development to show that the CoI 
framework is both useful and strong in relation to its theoretical foundation (Garrison 2011, 2012, 2013). Vaughan and Garrison (2006) also utilise the CoI framework as as a theoretical and analytical framework for faculty development. In line with this, we also use the framework as a way of organising our analysis rather than measuring element within the platform content. This paper has taken the overall elements of the framework for an exploratory qualitative analysis of staff feedback. We have adapted CoI to use as a descriptive analytical theory, as it aimed to help describe participant's engagement and how the online community worked. The social, cognitive and teaching elements of online communities (see appendix A) were insightful to help categorise and gain insight to the type of staff engagement within the pilot SocialLearn community.

Other frameworks were considered but many had a principal focus on cognitive elements (Vrasidas and McIsaac 1999), or were found difficult to apply for practical analysis (such as Wenger's (1998) 'communities of practice'). The CoI framework elements that included social, cognitive and teaching dimensions of online communities could be seen throughout the group content, the communications between staff and the overall group cohesion.

The paper now goes on to outline feedback from the focus groups, followed by the feedback from the survey. The paper then discusses this feedback within the framework of social, cognitive and teaching outcomes. This is followed by an outline of the key learning points taken from the project for those hoping to build a successful online staff community.

\section{Focus Group Findings - the possibilities linked to an online community}

\subsection{The importance of online engagement for staff}

Overall, there was a general appetite for an online community from the pilot group. At the time of the focus groups, the majority of ALs did not feel that they were part of a general AL community:

"you don't feel part of the professional community because you don't know the people". (FG2)

As ALs experienced disconnection, they expressed both the need and desire to connect to other tutors in some way. Many of the participants engaged with social media already. Facebook and LinkedIn were the most popular, with only about four people on Twitter. There were only two ALs (one in each group) who said they wrote a blog (in one focus group there was confusion to what a blog was). About a third of participants actively tried not to engage with any social media in a significant way. However, all but one participant said they would be willing to try SocialLearn. This is a very important point in that there was a general willingness from the pilot group to try and build some type of AL academic and social community:

"I've been an AL a long time and an OU student a long time and isolation is a problem and the idea of being able to talk to a very particular group of people attracts me". (FG1) 
"we've had our awareness raised about it, go on and try it out. I'm willing to get into this pilot I'm not a great one for social media but I'm absolutely willing to find time here and there to have a look at this and contribute and see where it goes". (FG2)

Importantly, SocialLearn was seen as having a particular role in enhancing face-toface communication although the group generally felt that online engagement must augment face-to-face social interaction that rather than replace it. ALs liked the idea of online professional engagement and focused social communication.

There was a minority of ALs in the focus groups who were active champions of social media. They were quite vocal in advocating the use of social media for ALs on a personal level. The potential of the SocialLearn platform was discussed as a tool to support professional, social and learning development.

Among the main advantages of using social media highlighted, included personal development, with ALs highlighting the opportunities to publish and advertise their work, as well as becoming more visible in their subject area, finding employment (one AL mentioned that they had received three job offers through LinkedIn), and managing online reputations. It was therefore clear that SocialLearn could be an arena to share professional, research and scholarship interests in this way. This shows the potential of establishing a CoI due to the willingness to develop an integrated social, cognitive and teaching platform.

In Focus Group 2 there was a key theme of increasing the "voice" of ALs. Some ALs expressed the desire for more engagement with full time OU faculty staff, such as their line managers (in the OU these are Staff Tutors or Senior Faculty Managers) as well as those directly involved in curriculum and module development, and a forum to share their views on particular courses. Although OU Forums were seen as a route to do this, it emerged from the focus groups that ALs felt these were too large and some ALs indicated a general sense of detachment, highlighting the presence of loud and dominant voices within them:

"I would agree and I think ALs need a voice. For example, students get a survey and give all their comments and give their feedback, now when do we ever really". (FG2)

For this to work there would need to be a high-level of engagement from the OU in general. An online staff community could also be seen as an opportunity to engage with the wider teaching institution.

The benefits of using social media also included key social interactions. For example it was seen as a medium to communicate with other ALs, arrange face-to-face 'meetups', find people with similar interests and engage on a social level. Overall it could, "plug a gap in finding out what ALs are actually doing" (FG1) and "make people human" (FG2). Furthermore, engaging with people on a day-to-day basis could be seen to help some participants feel less isolated.

One of the main benefits has been access to a "wealth of links". Some ALs would like to share people's research interests and establish connections with other staff 
members, particularly related to opportunities for research grants for example. There was also an element of linking people to useful information. ALs said they would be more inclined to use SocialLearn for professional outcomes linked to the content. Lectures, conferences and events were also popular potential shared topics as well as social events.

The above evidence shows there is a desire for some kind of AL community and strengthening and enhancing professional, social and learning opportunities were seen as possible outcomes. There were a number of interesting advantages expressed in regards to being engaged with an online community but there were also questions around the expectations of the frequency of engagement as well as the consequences of non-engagement. This was set as a question of what type and level of participation was expected from ALs.

\subsection{General mistrust of social media}

Although many ALs involved in the focus groups used social media in some way, a number of other ALs expressed some kind of distrust in regards to social media. Issues of mandatory involvement in social media for ALs, monitoring and privacy were key themes that were raised in this regard. These were all linked to an overall questioning of the use of social media by other users:

[talking about Facebook and Twitter] "I've consciously avoided them because I don't want that kind of contact with the general population that talk about absolute $s^{* * *}$ most of the time, and when they don't do that they lend themselves towards litigation". (FG1)

There was an underlying hint of suspicion in regards to social media in both focus groups. This was underlined by a concern of the fast pace of technological change in general working life. ALs felt that online engagement was becoming more pronounced in their teaching very quickly. Indeed, there was almost an argument between two ALs in focus group one in regards to the use of social media for "good" or for "bad". Trust is an important element of building the social presence for a CoI (Garrison 2011) but the focus group findings reflect an environment of distrust.

\subsection{SocialLearn as "mandatory"}

The lack of trust reflected the concern that the engagement with the platform may be mandatory. ALs expressed an immediate concern as to whether their engagement would be monitored on the platform: would someone from the OU be recording those who engaged and those who did not? This was linked to ALs trying to understand the expectations of their involvement in the platform.

ALs did not like feeling forced to engage with social media. Engagement needs to be voluntary:

"I mean ultimately if I was forced to take part in any social media platform, I would tell them to go and (!**!) because nobody will never be coerced or forced whether it's by contract or not to take part in discussing my own views". (FG1) 
In regards to SocialLearn, ALs were concerned because the information and encouragement to engage with SocialLearn came from an OU Staff Tutor who had line-management responsibility for many of the study participants. Any potential mandatory expectations linked with use of social media were met with reserve:

"is there an expectation there that I'm supposed to be committed to this, because I would feel much more comfortable if there wasn't an expectation that I have to give an immeasurable amount of time to it because my time is so precious as it is, with so many different commitments work-wise, personally and so forth, but I'd feel very comfortable about it being a comfortable friendly place where you can pop in and out and join things and so forth" (FG1).

To combat this, Focus Group 2 participants discussed the need for reassurance from the OU and to set out guidelines and principles in regards to engagement with a new online community.

\subsection{Privacy and Social Media}

In the focus groups there was particular concern about who would have access to private communities. First, ALs did not wish to engage if they had to worry about not being candid in their responses. There was also concern regarding the involvement of lone-management staff such as Staff Tutors in any potential AL community:

"that's a serious issue if you feel that people from within your employment organisation have the possibility to know how I act professionally may be very different to how I might vote politically and I think there is a serious issue there". (FG1)

There was an explicit request for reassurance in regards to comments and other engagement being private and that this would not be monitored by line managers.

The ALs involved in the pilot were also clear that they wanted their postings in the community to be private, that is restricted to the relevant community. However, the permissions and connection options in SocialLearn are so confusing that people did not know who had access to collections and postings. After making everything 'private', a person not part of the community was able to comment on the Scottish Independence debate collection that had been established to encourage engagement with the platform. This is one of the more important and pressing issues to get right if the SocialLearn platform is to be a viable place to build an AL community, especially as students also have access to the platform. Privacy options must be clear and manageable. 


\subsection{Barriers to using Social Media}

Among the barriers to using social media identified included potential technical difficulties. There was a sense of a "generational problem" felt by some ALs who were struggling to keep up with the fast pace of social media innovation. First, access to these platforms was crucial to their success, and they had to be very simple to access and use:

\section{"when I'm in front of that blasted machine, arguable after a few seconds, if there isn't a button that is really colourful, then really I'll start to lose interest". (FG1)}

There were also practical time related issues as the demands of teaching and social media compete. This an interesting finding in light of the CoI framework where teaching precence is seen to enhance social presence rather than compete with it (Garrison at al. 2010). Motivation for using platforms dropped when there was a lack of engagement and response to posts.

There were also varied understandings on what the platform was to be used for and mixed expectations in regards to social media where there are multiple platforms and forums with underlying expectations to engage with them all. With these multiple platforms comes a large amount of information and some ALs found it difficult to pick out key and important messages.

ALs were further concerned about the engagement of other staff members and students. ALs thought other media sites were often used as a platform for others to complain or vent their issues. If the platform was seen as a social site for ALs they were worried about student access.

Therefore technical issues, time constraints, other people in the online community and mixed messaging around the use of social media were seen as the key barriers to creating a successful social and learning community.

\section{Findings: Survey results}

\subsection{Staff feelings of belonging to a wider professional and social community}

The ALs involved in the SocialLearn pilot were asked to consider the extent to which they belong to a wider professional and social community. In terms of belonging to a wider professional community opinion was generally positive with $45 \%$ considering this as either mostly or somewhat true, however $50 \%$ of ALs were more cautious and indicated that this was only slightly true for them. When asked about belonging to a wider social community a somewhat different picture emerges. Here opinion leaned more towards the partially true categories, with $37 \%$ opting for only slightly true whilst $27 \%$ indicated that this was not true at all. $27 \%$ also indicated that this was somewhat true and only $9 \%$ leaning towards mostly true. These are encouraging results given the context of home working and the potentially remote nature of the AL role within the OU.

Figure 1: Do ALs belong to a wider professional community? 
Completely true; $0 \%$

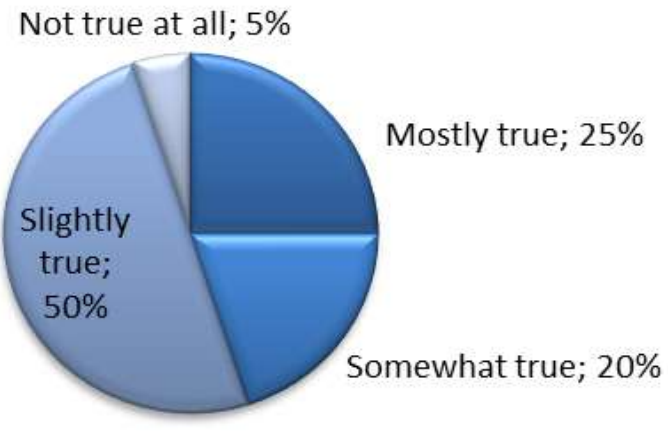

Figure 2: Do ALs belong to a social community?

Completely true; $0 \%$

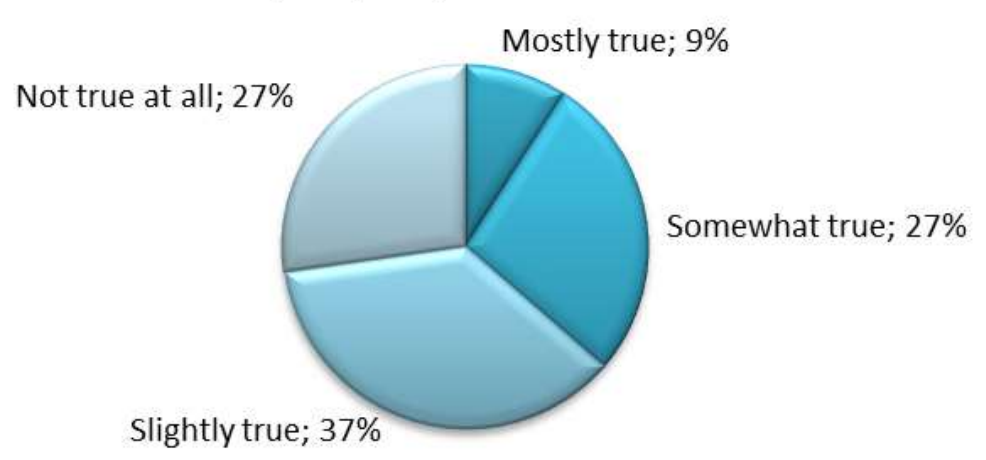

One general observation that can be made here is that there is a disparity between ALs feeling that they are more likely to belong to a professional community as opposed to a social community. This perhaps reflects the interdependency of the elements within the CoI framework. Yet, overall, the results do suggest that ALs only partially feel that they belong to a both a social and professional community.

\subsection{Social Media engagement}

The survey results mirrored the focus group finding that there was some engagement with social media from ALs but this was not all encompassing or comprehensive, suggesting a disparity between those who use social media and those who do not. The most used media were the OU forums at $31 \%$ followed closely by Facebook at $28 \%$. One key finding is that only $19 \%$ of those who completed the survey had engaged with SocialLearn.

Figure 3: AL engagement with social media 


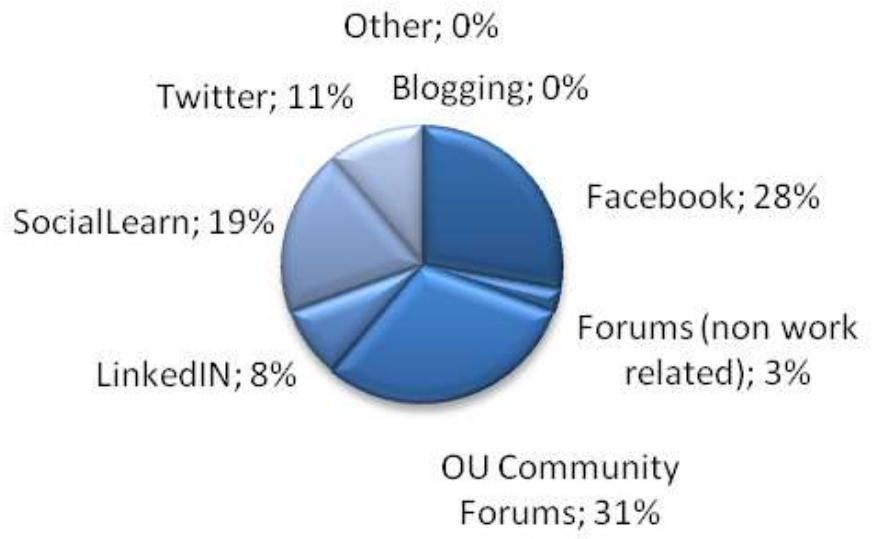

\subsection{Engagement with SocialLearn}

Over $50 \%$ of those who completed the survey had a very positive $(16 \%)$ or somewhat positive (37\%) engagement with SocialLearn. 16\% had a negative engagement and $5 \%$ very negative. Not everyone found their engagement with SocialLearn easy with those surveys giving a median rating of 4 (with 0 being not at all easy to use and 10 being easy to use). This also reflects general concerns expressed at the initial focus groups that highlighted the difficulties with functionality and ease of use barriers and concerns around using social media and SocialLearn.

Figure 4. Ease of engagement with SocialLearn

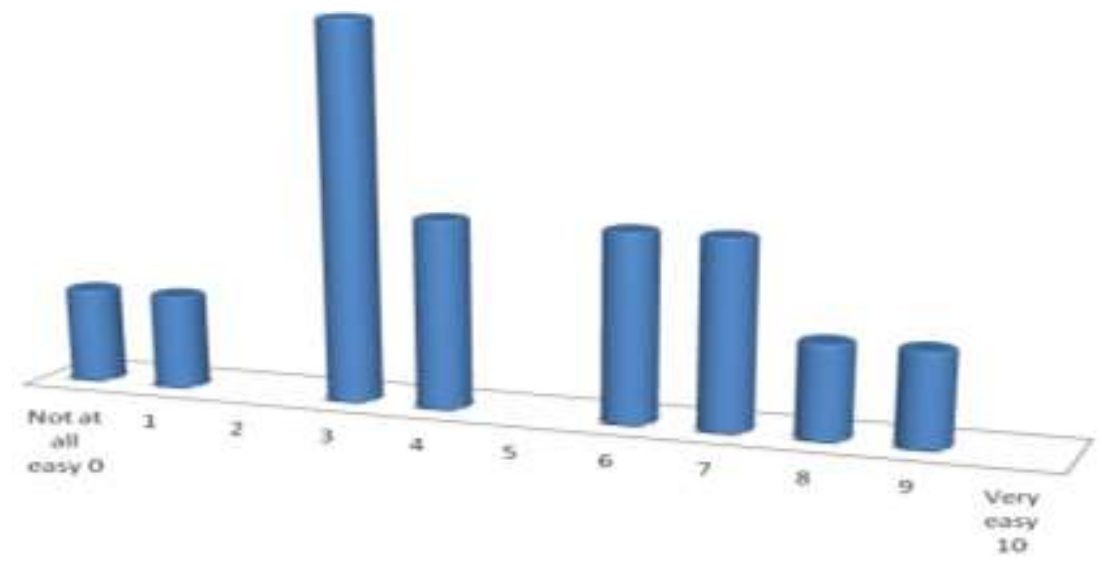

6.4.Barriers and concerns around using Social Media and SocialLearn

Time constraints proved to be one of the main barriers to participation in an online CoI and $81 \%$ of ALs agreed that they would have difficulties finding the time and $36 \%$ indicated that they strongly agreed that they just do not have the time to participate. Issues around finding time to participate can be linked with AL use of other OU platforms. Here 62\% (29\% strongly agreeing and 33\% agreeing) indicated that they currently use too many platforms, whilst only $14 \%$ disagreed. Interestingly $34 \%$ of ALs remained undecided on wither or not they currently use too many platforms in their work with the OU. Although, it remains clear that time remains a 
key issue. Opinion was more evenly divided when asked about how worried ALs were about line management monitoring AL online activity, with those who generally agreed and disagreed evenly balanced at $45 \%$. We also see a similar even split in opinion when ALs were asked if they would, 'Feel obliged to participate' with $33 \%$ agreeing and also disagreeing. Feeling obliged to participate is also linked with concerns around the potential mandatory nature of social media/SocialLearn and $55 \%$ of ALs were concerned about this issue and within this figure $40 \%$ of ALs strongly agreed that the potential mandatory nature of participation would be unwelcome, this is in contrast with $30 \%$ who broadly disagreed and did not consider this to be an issue for them. It is evident here that a social presence online could potentially be compromised and/or reshaped if participation was mandatory. This is compounded by a related concern amongst ALs that about maintaining the separation between private and work lives, here 30\% remained neutral on this question and 55\% broadly agreed that this is an area of potential concern.

Figure 5: Would ALs feel obliged to participate?

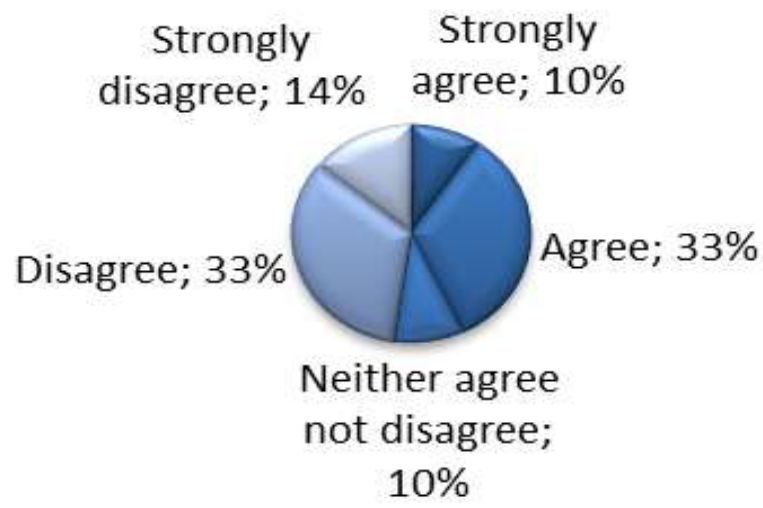

When we move onto issues around trusting social media AL opinion was once again evenly split. Here $41 \%$ of ALs agreed that they do not trust social media, whilst $41 \%$ broadly disagreed. There are also some interesting variations in AL opinion when asked wither or not ALs actually liked using social media. In response to this question $35 \%$ disagreed and 15\% strongly disagreed, whilst 35\% agreed and 15\% remained neutral. Issues around online privacy are also linked with this theme and here $50 \%$ (30\% strongly agreeing and $20 \%$ agreeing) of ALs were generally worried about this issue compared to $25 \%$ who were not. Although $25 \%$ of ALs were undecided and remained neutral on this issue.

\subsection{Desired content of an online community}

Firstly, when asked if an online community should be a general social space for ALs only $38 \%$ indicated that this was not important and the majority of ALs considered this as somewhat important (43\%) and very important (14\%).

A second key theme is linked with AL expectations around the use of an online community to enhance both social and professional interaction and development. The majority of ALs indicated that it is somewhat (52\%) and very important (24\%) for an online community to facilitate interaction with other OU staff. There was also a desire to see an online community that could be used to keep up to date with AL and OU 
related news/events. This was considered as somewhat important by $57 \%$ and very important by $24 \%$ of respondents. This picture is generally mirrored when asked about using an online community as a place to share and sign up for social events, with $35 \%$ considering this not important and $65 \%$ broadly in favour. Using an online community as a hub to share and discuss professional and research related activities was favoured by $95 \%$ of respondents, with $33 \%$ considering this very important and $62 \%$ somewhat important. Here the cognitive aspect of an online presence is very evident, although it is worthwhile noting that in both areas approximately a quarter of ALs who responded were not in favour.

A third key theme is the use of an online community to allow ALs to interact with students and build a teaching presence. Only $24 \%$ felt that it was somewhat/very important to use an online community as a shared space to interact with students, with the majority (76\%) indicating that this was not an important aspect of an AL online community. When asked about replacing tutor group forums $76 \%$ also indicated that this was not important. However, one key point to bear in mind here is that ALs already have a strong teaching presence and engage with students through various OU online platforms as well as via face to face tuition, phone contact (landline and SMS texts) and e-mail.

\subsection{General survey feedback}

The survey also asked two open-ended questions that focused on drawing out suggestions to help build an AL community in Scotland, as well as asking for general comments on the survey. When asked about building an AL community in Scotland, those who responded offered a diverse range of suggestions. These included practical recommendations that highlighted the need for the $\mathrm{OU}$ to focus more on building social interaction into the AL role, especially when attending training events and offering more opportunities for ALs to meet up. Here some respondents indicated that platforms such as SocialLearn can play a key role in facilitating more meaningful interaction between ALs.

Several comments also identified wider areas of concern that would underpin the move towards online communities. It was noted by one respondent that the AL role is geared towards working independently and this accelerates isolation. The AL noted that:

“...My own personal contact is limited (i.e. with colleagues), physical contact even more so. As a new AL I thought it strange, now I accept it as being part of the $O U$ in a culture which has contributed to this scenario. I'm unsure if changing this via SocialLearn will be easy. "(Social Learn Survey May 2013)

Another respondent expressed concern about the blurring of social and professional roles, suggesting that:

"...I can understand the argument for an improved professional platform, but my friends are not often my colleagues and I do not understand why this social aspect is being pushed."(Social Learn Survey May 2013) 
Finally, it was also suggested that platforms such as SocialLearn need to consider different ways to access the online content. One AL noted that:

"The key to all social media is access through smart phones. I only use $S M$ [social media] (FB, Twitter) etc. that I can access this way and rarely use a PC for this. "(Social Learn Survey May 2013)

Finally, ALs were generally positive about the need for platform consolidation and better interaction but (echoing focus group comments) did find the beta version of the SocialLearn platform difficult to use. Issues of finding time to engage with such platforms were also a common theme that underpinned the open comments.

Key to moving the SocialLearn project forward is future engagement and ALs were asked about the possibility of this. Here the majority of ALs retained a generally cautious approach when asked about their future engagement with SocialLearn, with over half undecided (57\%) about the platform, although 33\% did indicate an interest in future engagement. A small minority (10\%) indicated that they would not be using SocialLearn in the near future.

\section{Discussion}

\subsection{Social Presence}

The difficulties of establishing a 'social presence' was by far one of the most significant aspects for building a staff community. Indicators of a strong social presence include self-projection, expressing emotions, group identity and collaboration (see appendix A). The participants within the focus groups made it clear that they wanted a social element within the online community, but the purpose of this had to be clear. However, there were no guidelines or set purpose attached to the online community and the SocialLearn platform in general was a confusing hybrid of social media outputs and links. Garrison et al. (2010: 32) have established that social presence cannot be established without a clear professional purpose because it is a mediating element and "a responsibility of teaching presence and a condition for creating cognitive presence (i.e., collaborative inquiry)". Therefore, social presence is interdependent in regards to the teaching and cognitive aspects of the community. This increases the importance of a clear purpose and leadership within the community.

In integrating a social element into the online community, staff were worried about developing their own 'social presence'. As the platform was set up with general outcomes in mind, the lack of clarity of purpose made the social element of the online staff community an area of anxiety.

For example, in regards to group identity and collaboration, this was seen throughout the SocialLearn discussions through the six month period. One of the most popular threads for debate was titled 'Scottish Independence: Aye or Nay (yes or no)', which unsurprisingly was highly politicised. Furthermore, one of the most popular ways in which to share information was to market and sign up for social events, such as a Christmas night out. Despite the high levels of social engagement, many ALs had expressed worry about sharing political affiliations in what was both a social and work space. Aspects of open communication and risk-free expression were one of the 
priority worries for staff, especially within the focus groups. This is an important barrier, as developing social presence is dependent on a trusting environment and an ability to develop personal and affective relationships (Garrison 2011: 34).

Overall, the social element and potential of SocialLearn remained the most significant elements for the AL staff in the survey. However, when this belays a more complex picture of the dynamic relationship between the presences in the CoI framework (Garrison et al. 2010) and one important observation that can be made here is that there is a disparity between ALs feeling that they are more likely to belong to a professional community as opposed to a social community. Yet, overall, the results do suggest that ALs only partially feel that they belong to both a social and professional community. This has the potential to weaken the development of a social presence online for several reasons. Firstly, the AL role within the OU is organised around a structure that builds social isolation into the role (despite numerous and varied efforts to achieve the opposite), partially due to the high level of individual autonomy given to ALs.

This suggests that there is already a relatively high level of prior social disengagement amongst ALs and this would need to be addressed through other initiatives if a full social presence online is be sustained. Secondly, the survey also suggested that there are a range of significant barriers that could potentially undermine the use of an online social/professional platform. For example, the majority of ALs are concerned about having the necessary time to spend developing and maintaining an online social presence. This is also compounded with concerns that there are already a myriad of platforms in use at the OU and other social media used in a personal capacity. If open communication is taken as a key indicator of a social presence online, then the ALs in both the focus groups and survey expressed reservations about the blurring between social and professional boundaries. This dilemma was shown by the survey respondent above when talking about the argument for an improved professional platform. This perhaps outlines the interdependence of social presence with the development of cognitive and teaching presence. Social presence is a mediator for the other presences (Garrison et al. 2010) and all three would need to be developed for effective professional development

Despite these caveats, the social presence was one of the most developed elements of the staff online community. Overall, there appears to be a desire for a meaningful online community that helps develop a social presence for ALs but this is also underpinned by some significant reservations with social media and online working in general.

\subsection{Cognitive Presence}

For a strong cognitive presence, indicators included information exchange, connecting ideas and applying new ideas. There was an element of this within the community. There was the establishment of a 'collection' where ALs could exchange research interest and ideas. This had some success with some ALs sharing the focus of their work with others. However, there was a failure to generate any new ideas of research projects from this. The thread did not develop and become interactive or dynamic. There was no clear champion or leader for this collection, and lack of promotion and clear outcome for involvement hindered this collections development. 
However, there was a significant interest in the cognitive presence of the online community, especially around professional development. The survey indicated that sharing research interests still remained important to ALs in an online community. In one of the focus groups the potential of self-promotion was emphasised. It could be concluded that the cognitive element of an online staff community was seen as important, even if it was left underdeveloped within the SocialLearn pilot. Cognitive presence is shaped by the other framework elements (Garrison et al. 2010) and the lack of development could have hindered the platform engagement in general.

\subsection{Teaching Presence}

At the beginning of the pilot there had been a further goal of inviting students to engage on SocialLearn in a separate student community. Due to some technical difficulties at the beginning of the project this did not occur. However, it had been hoped that ALs would also use SocialLearn as a platform to support students as well as a place to share teaching practice, design and methods with colleagues.

Of all the elements of a successful 'Community of Inquiry' (CoI) this was the least developed presence. This could have hindered the development of the community because "a community of inquiry requires a thoughtful, focused and attentive teaching presence" (Garrison et al. 2010: 32). The indicators for teaching presence included setting up and exchanging teaching methods and practice and helping others to resolve issues (see appendix a). ALs did not share or even try to discuss student and teaching practice in the pilot community. One significant explanation for this is that ALs have always used the OU online forums for this. The survey also indicated that most respondents did not see SocialLearn as a replacement for this. Therefore, the expectations of creating a community of academic practice remained unfulfilled with the lack of teaching presence.

It has been acknowledged that teaching requirements and roles are changing (Cleveland-Innes 2013) and in regards to the wider OU context, the roles of ALs and online teaching expectations have been evolving. The anxiety shown in the focus groups were related to the potential expectations of the $\mathrm{OU}$ in regards to teaching. In light of teaching change, "realistic expectations of the role of faculty and how much, and how fast, changes may be made in teaching are required" and a context of support and reward must be in place to make change effective (Cleveland-Innes 2013: 390). The SocialLearn platform did not particularly acknowledge this changing role before the pilot began. For an effective online staff community the reward and context of the teaching role would have needed to be developed.

The underdevelopment of the teaching presence (which revolves around facilitation and direction) underpins the lack of leadership noted in the discussion above. Garrison et al. (2010) suggest that once the teaching presence is more established this could be a driver for all the other elements in the community. Therefore, clear leadership is clearly needed to create an online staff community.

\section{Learning Points for future online staff communities}

Firstly, the privacy settings of an online community must be set out clearly at the beginning. Those that have potential access to the community must be communicated 
and set out clearly. If the community is being monitored in any way it must also be stated in advance. By offering this transparency this could help alleviate potential user worries over privacy and monitoring. Expectations also need to be established/made clear from the outset of creating online academic communities. In line with this, the wider teaching context must acknowledged to establish realistic expectations. Issues around mandatory use cannot be linked to the expectation of social elements within a community. If this is clear at the beginning this can assuage any worries from the potential user group.

Further to this, there must be clear and effective leadership for all elements of the teaching community. The discussion shows that the lack of development in the teaching and cognitive presence of the online community hindered the development of the social presence and community in general. Garrison et al. (2010) show in particular the central role of the teaching presence in creating and sustaining the other elements of the community. In regards to the CoI framework in general, this was useful and insightful model to help reach deeper insights into the potential of online staff communities. Garrison et al. (2010) note the growing interest in the CoI framework and its potential. What this paper has shown is its applicability not just to students but also wider staff learning outcomes.

The online platform must be quick and easy to access and use. If a tutorial is required to use it, it will not work. Success often rests on the ability to keep sustained, purposeful interaction (Zingaro and Oztok 2012) and this was also true of an online staff community. The SocialLearn platform was visually accessible but users struggled with new concepts such as 'collections' and access paths were not at first obvious. This is particularly important in a world of where social media appears to be ever gathering more pace. Furthermore, any online platform must be augmented with other types of contact such as face-to-face contact, e-mails and the use of other media to maintain momentum and engagement. The establishment of a successful online academic platform must include an overall communication plan for the user group as well. Multi-level communications can keep momentum and interest in the online community.

Finally, the nature of the potential audience or users is very important. In this case, the context of changing tutor roles around online and blended learning must be considered in conjunction with the creation of academic communities. There is also the element of users negotiating and managing their 'self' online. When creating a potential online academic community the nature of the audience must be considered in advance.

\section{Conclusion}

Overall, this pilot has given valuable insight to the creation of online academic communities. It has shown clearly that there is potential in this area. The paper outlined some insight to the importance of different elements within a staff online community. The social presence of staff was seen as a priority, followed by cognitive and then teaching elements.

To create a successful online staff community, issues around privacy, online expectations and potential users of the community should be overt and transparent. 
This must coincide with a clear acknowledgement of the learning and teaching context. Furthermore, strong leadership is necessary for the social, teaching and learning elements within the community due to their interdependency. This would help overcome barriers that users may have to engaging in online communities. The nature of the audience matters very much for the uses of an online staff community and it must be embedded in a multi-level communication strategy to really engage a wide set of potential users.

Our conclusion is that there was appetite for a dynamic and effective online staff community from the pilot group. The online platform SocialLearn that was utilised, however, was not dynamic or quick enough to be viable for time-constrained users. We would encourage more research in this area in an era where online teaching growing at such a fast pace. We would also like to see further application of the CoI framework to online staff communities. As we look to enhancing online student experience, we should also encourage the development of platforms which can provide teachers with a means of support as well as enhancing online teaching experience. 


\section{References}

Akyol, A. and Garrison, R. (2008) 'The development of a community of inquiry over time in an online course: Understanding the progression and integration of social, cognitive and teaching presence', Journal of Asynchronous Learning Networks, Volume 12: Issue 3-4

Akyol, Z., and Garrison, D. R. (2013) (Eds.) Educational communities of inquiry: Theoretical framework, research and practice. Hershey, PA: IGI Global.Anderson, M., Maier, L. and Shepard, M. (2010) 'Skepticism to Success: Meeting critical workforce needs through innovation and collaboration', Journal of Asynchronous Learning Networks, Volume 14: Issue 3

Annand, D. (2011) 'Social Presence within the community of Inquiry framework', The International Review of Research in Open and Distance Learning, Vol. 12, No. 5.

Brouns, F., Berlanga, A.J., Fetter, S., Bitter-Rijpkema, M.E., van Bruggen, J.M. and Sloep, P.B. (2011) 'A survey on social network sites to determine requirements for learning networks for professional development of university staff', Int. J. Web Based Communities, Vol. 7, No. 3, pp.298-311.

Chu, C.M. (2005) 'Web-based communities scholarship: from silence to dialogue', International Journal of Web-Based Communities, Vol. 1, No. 4, pp.423-435.

Cleveland-Innes, M. (2013) 'Teaching in an Online Community of Inquiry: Faculty Role Adjustment in the New Higher Education' in Akyol, Z., and Garrison, D. R. (Eds.) Educational communities of inquiry: Theoretical framework, research and practice. Hershey, PA: IGI Global, 389-400

Donovan, C., Hodgson, B., Scanlon, E. and Whitelegg, E. (2005) 'Women in higher education: Issues and Challenges for part-time scientists', Women's Studies International Forum, Vol. 28, pp. 247-258

Fontana, Lynn A. (1997) 'Online Learning Communities. Implications for the Social Sciences' in Martorella, Peter, H. (ed) Interactive technologies and the social studies: emerging issues and applications, Albany: State University of New York Press.

Garrison, D. R. (2011) E-Learning in the 21 st century: A framework for research and practice (2nd ed.). London: Routledge/Taylor and Francis.

Garrison, D. R. (2012) Social presence within the community of inquiry framework. International Review of Research in Open and Distance Learning, 13:1, 250-253

Garrison, D. R. (2013) 'Theoretical Foundations and Epistemological Insights of the Community of Inquiry', in Akyol, Z., and Garrison, D. R. (Eds.) Educational communities of inquiry: Theoretical framework, research and practice. Hershey, PA: IGI Global, 1-11 
Garrison, D.R., Anderson, T and Archer, W. (2000) Critical inquiry in a text-based environment: Computer conferencing in higher education. The Internet and Higher Education 2(2-3): 87-105, 2000.

Garrison, D.R. and Anderson, T. (2003) E-Learning in the 21st century: A framework for research and practice. London: Routledge/Falmer, 2003.

Garrison, D. R. and Arbaugh, J. B. (2007) Researching the community of inquiry framework: Review, issues, and future directions. Internet and Higher Education 10(3): $157-172$

Garrison, D. R., Cleveland-Innes, M., and Fung, T. S. (2010) Exploring causal relations among teaching, cognitive and social presence: A holistic view of the community of inquiry framework. Internet and Higher Education, 13:1-2, 31-36.

Garrison, D. R., Cleveland-Innes, M. and Vaughan (2013) The Communities of Inquiry, https://coi.athabascau.ca/, accessed 11/11/13

Goffman, E. (1959) The Presentation of Self in Everyday Life, New York: Anchor Books.

McInnerney, J. M., \& Roberts, T. S. (2004). Online Learning: Social Interaction and the Creation of a Sense of Community, Educational Technology \& Society, 7 (3), 73 81 .

Palloff, Rena, M. and Pratt, Kieth. (2005) Collaborating Online. Learning Together in Community, San Francisco: John Wiley and Sons

Palloff, Rena, M. and Pratt, Kieth. (2007) Building Online Learning Communities: Effective Strategies for the Virtual Classroom ( $\left.2^{\text {nd }} \mathrm{ed}\right)$, SanFrancisco: John Wiley and Sons.

Pereira Coutinho, C. and Santana Lisbôa, E. (2013) 'Social networks as spaces for informal teacher professional development: challenges and opportunities', Int. J. Web Based Communities, Vol. 9, No. 2, pp.199-211.

Scott, H. (2007) 'The temporal integration of connected study into a structured life', Grounded Theory Review, 6:2, 95-115

Thatcher, C., Straker, L. and Pollock, C. (2011) 'Establishing and maintaining an online community of academics: longitudinal evaluation of a virtual conference series', Int. J. Web Based Communities, Vol. 7, No. 1, pp.116-135.

Ubell, R. (2010) 'The Road not Taken: The Divergence of Corporate and Academic Web Instruction', Journal of Asynchronous Learning Networks, Volume 14: Issue 2

Vaughan, N., \& Garrison, D. R. (2006). How blended learning can support a faculty development community of inquiry, Journal of Asynchronous Learning Networks, 
10:4, 139-152Vrasidas, C and McIsaac, M.S (1999) 'Factors influencing interaction in an online course', American Journal of Distance Education, 13:3, 22-36

Wenger, E (1998) Communities of Practice: Learning, Meaning and Identity, Cambridge: Cambridge University Press

Zingaro, D. and Oztok, M. (2012) 'Interaction in an Asynchronous online course: A synthesis of Quantitative indicators, Journal of Asynchronous Learning Networks, Volume 16: Issue 4 
Appendix A - The Community of Inquiry (CoI) frameworks three main elements

\begin{tabular}{|lll|}
\hline Elements & Categories & Indicators (examples) \\
\hline Social Presence & Open Communication & Learning Climate/Risk- \\
& Group Cohesion & Free expression \\
& Personal/Affective & Group \\
& & Identity/Collaboration \\
& & Self projection/expressing \\
& & emotions \\
\hline Cognitive Presence & Triggering event & Sense of Puzzlement \\
& Exploration & Information exchange \\
& Integration & Connecting ideas \\
& Resolution & Applying new ideas \\
\hline Teaching Presence & Design \& Organisation & Setting Curriculum \& \\
& Facilitating Discourse & Methods \\
& Direct Instruction & Shaping Constructive \\
& & Exchange \\
& & Focusing and Resolving \\
& & Issues \\
\hline Source: Aykol and Garrison $2008, p 4$ & \\
\hline
\end{tabular}




\section{Appendix B - SocialLearn Platform}

OIf

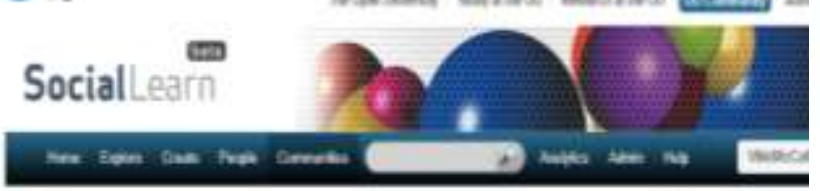

9. Sociat Sciences Acadumic Engagement Plilot Community

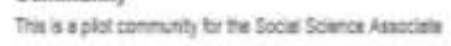

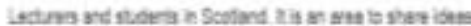

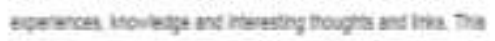

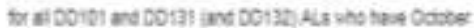

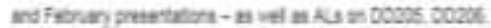

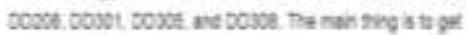

orra grod ond porg and raeter:

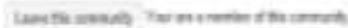

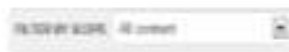

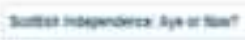

wis

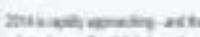

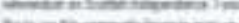

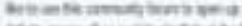

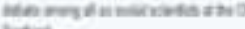

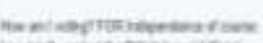

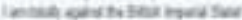

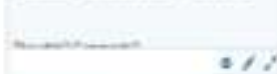

4

thon ant

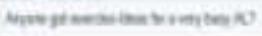

smentins

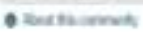
- Derminimis

4

of

(2)

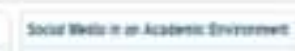

Social Media in an

Academic

Environment

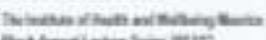

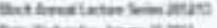

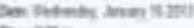

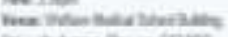

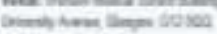

Congenten iones

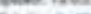

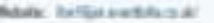

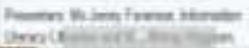

Ine itumea in angie

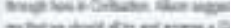

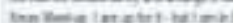

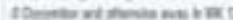

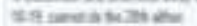
anemipte

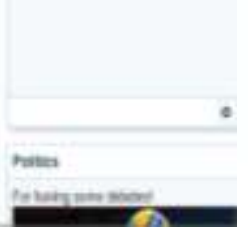

andarm seromatasede

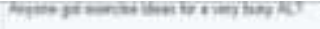

$=0$,

maresing the

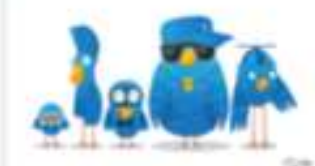

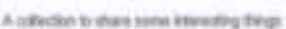

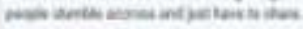

wigurstem

maumy arfin wegs

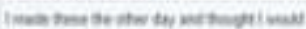

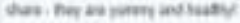

nets

harthata mas:

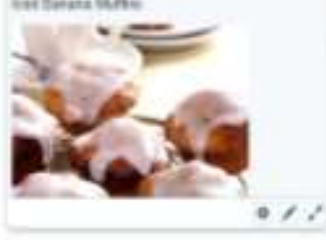

Dis As Beciat anm

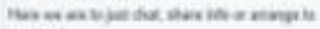

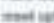

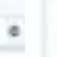

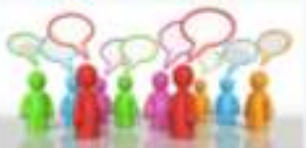

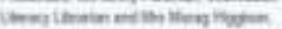

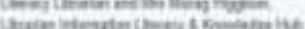

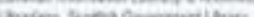

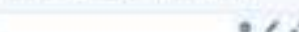

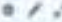

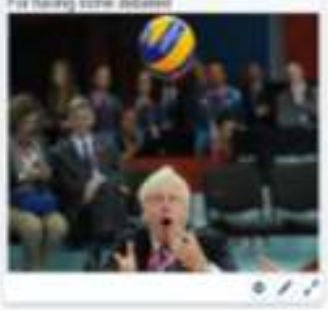

Honame marouts

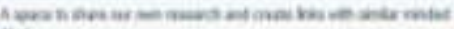

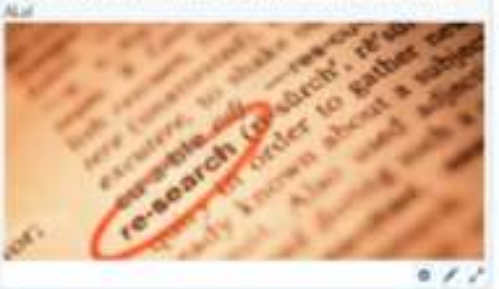

Ras ant Heroest

AL Fmass aone

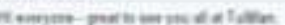

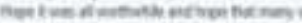

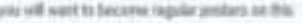
culson imiming

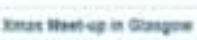

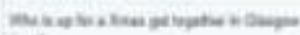
0,2

-

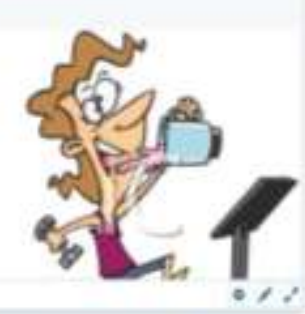

Ou heeat Mnentivy mesey

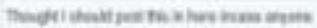


Appendix C - SocialLearn Analytics, November 2013- April 2013

\begin{tabular}{ll}
\hline Type of Activity & Amount \\
\hline Collection & 6 \\
\hline Event & 3 \\
\hline Thought & 4 \\
\hline User & 55 \\
\hline Commented & 51 \\
\hline Tagged & 43 \\
\hline & \\
\hline User Breakdown & Amount \\
\hline Number of users & 55 \\
\hline Active Users & 17 \\
\hline No. of people with friends & 2 \\
\hline No. of people with no friends & 52 \\
\hline Average no. of friends & 4 \\
\hline No. of people with followers & 13 \\
\hline No. of people with no followers & 41 \\
\hline Average no. of followers & 10 \\
\hline
\end{tabular}

